Preprint from Nucl. Instr. Meth. in Physics Research B 206 (2003) 1042-1046.

\title{
ANNEALING BEHAVIOR AND LATTICE SITE LOCATION OF Er IMPLANTED InGaN
}

\author{
E. Alves ${ }^{1,2}$, U. Wahl ${ }^{1,2}$, M.R. Correia ${ }^{3}$, S. Pereira ${ }^{3}$, B. De Vries ${ }^{4}$, A. Vantomme ${ }^{4}$ \\ ${ }^{1}$ Instituto Tecnológico e Nuclear, Dept. Física, Sacavém, Portugal \\ ${ }^{2}$ CFN da Universidade de Lisboa, Lisboa, Portugal \\ ${ }^{3}$ Universidade da Aveiro, Dept. Física, Aveiro, Portugal \\ ${ }^{4}$ Instituut voor Kern- en Stralingsfysica, Leuven, Belgium
}

\begin{abstract}
Single crystalline InGaN epilayers with different In content were implanted with $\mathrm{Er}^{+}$fluences in the range of $1 \times 10^{13}$ to $5 \times 10^{15} \mathrm{~cm}^{-2}$ at room temperature. The structural changes and lattice site location were studied with emission channeling and RBS/channeling. Photoluminescence measurements were also performed to study the optical properties of the implanted samples. After implantation of $1 \times 10^{13} \mathrm{Er}^{+} \mathrm{cm}^{-2}$, the emission channeling results show the incorporation of a significant fraction of $\mathrm{Er}$ in substitutional $\mathrm{Ga} / \mathrm{In}$ sites. For fluences of $1 \times 10^{15} \mathrm{Er}^{+} \mathrm{cm}^{-2}$ the aligned RBS spectrum along the [0001] direction reveals the displacement of the Er ions into random sites in the entire implanted region. Proximity cap annealing at $400^{\circ} \mathrm{C}$ and $500^{\circ} \mathrm{C}$ leads to some damage recovery on the samples implanted with lowest fluence accompanied by an increase of the substitutional fraction of Er. Despite the lattice disorder, a fraction of the $\mathrm{Er}$ ions are incorporated into optically active sites and luminescence emission was observed at 1.54 $\mu \mathrm{m}$ after annealing at $400^{\circ} \mathrm{C}$.
\end{abstract}

PACS: 68.55. Jk; 78.55. Cr; 82.80Yc.

Keywords: $\mathrm{In}_{1-\mathrm{x}} \mathrm{Ga}_{\mathrm{x}} \mathrm{N}$ layers, $\mathrm{Er}^{+}$doping, Photoluminescence, RBS/Channeling

\section{Introduction}

Among the nitride alloys InGaN has proven to be of crucial importance for the development of new optoelectronic devices due to its high luminescence efficiency [1]. Indeed the great potential of InGaN has emerged recently as one of the most important semiconductors for short-wavelength light emitting devices [2]. Moreover, by adjusting the nitride composition most of the visible part of the electromagnetic spectrum can be covered. However, despite the success of these alloys, there are still several open problems to solve in order to understand completely their properties and enhance the development of new device structures $[3,4]$.

Additionally, by incorporating optically active ions in InGaN we could extend its working wavelength range. Particularly Er-doped semiconductors are suitable for producing light sources operating at $1.54 \mu \mathrm{m}$ and optical amplifiers for optical fiber communications [5]. The emission at $1.54 \mu \mathrm{m}$ corresponds to the transition from the first excited sate $\left({ }^{4} \mathrm{I}_{13 / 2}\right)$ to the ground state $\left({ }^{4} \mathrm{I}_{15 / 2}\right)$ in $\mathrm{Er}^{3+}$. Erbium has an incomplete $4 \mathrm{f}$ electronic shell, which is screened by the outer-closed shells $\left(5 \mathrm{~s}^{2}\right.$ and $\left.5 \mathrm{p}^{6}\right)$ giving rise to rather sharp optical intra-4f electronic transitions almost independently of the host material. Moreover there is some evidence that the thermal quenching of the $\mathrm{Er}^{3+}$ related luminescence is reduced in wide band gap semiconductors such as $6 \mathrm{H}-\mathrm{SiC}$ and $\mathrm{GaN}$ [6-8]. These findings make InGaN alloys a promising host for Er incorporation. If it succeeds to integrate of light emitting diodes working from red to UV, lasers and detectors with Er-doped $\operatorname{In}_{\mathrm{x}} \mathrm{Ga}_{1-\mathrm{x}} \mathrm{N}$ emitting at $\sim 1.54 \mu \mathrm{m}$ will be possible. 
In this work we report the first lattice site location results obtained on Er implanted InGaN epitaxial layers. Films with two compositions were implanted and the evolution of the system with temperature studied.

\section{Experimental}

Nominally undoped wurtzite $\operatorname{In}_{\mathrm{x}} \mathrm{Ga}_{1-\mathrm{x}} \mathrm{N}$ films with different compositions and thickness were grown by metalorganic chemical vapor deposition on $\mathrm{GaN} / \mathrm{Al}_{2} \mathrm{O}_{3}$ substrates. The samples were implanted with a fluence of $1 \times 10^{15}{ }^{167} \mathrm{Er}^{+} / \mathrm{cm}^{2}$ at $150 \mathrm{keV}$. Before implantation the crystalline quality and composition were measured by RBS/C spectrometry. The measurements were performed using a $1 \mathrm{~mm}$ collimated $2 \mathrm{MeV}$ ${ }^{4} \mathrm{He}^{+}$beam with the samples mounted in a computer controlled two-axis goniometer with an accuracy of $0.01^{\circ}$. The backscattered particles were detected by two surface barrier silicon detectors placed at $160^{\circ}$ and close to $180^{\circ}$ with respect to the beam direction (Cornell geometry) and with energy resolution of 13 and $16 \mathrm{keV}$, respectively. To study the rare earth lattice sites, the emission channeling (EC) technique was combined with position sensitive electron detection [9]. For that purpose, radioactive ${ }^{167} \mathrm{Tm}\left(\mathrm{t}_{1 / 2}=9.25 \mathrm{~d}\right)$ was implanted with $60 \mathrm{keV}$ at the ISOLDE/CERN facility to a dose of $1 \times 10^{13}$ at $/ \mathrm{cm}^{2}$ within a $1 \mathrm{~mm}$ beam spot. ${ }^{167} \mathrm{Tm}$ decays into the excited nuclear state ${ }^{167 \mathrm{~m}} \mathrm{Er}\left(\mathrm{t}_{1 / 2}=2.27 \mathrm{~s}\right)$, and the lattice location of ${ }^{167 \mathrm{~m}} \mathrm{Er}$ was determined by monitoring the K, L and M conversion of 150, 199 and $206 \mathrm{keV}$ electrons emitted during its transition to the ${ }^{167} \mathrm{Er}$ ground state [10].

PL measurements have been performed with a Brucker 66V Fourier transform spectrometer. The signal was detected with a North-Coast EO-817 liquid nitrogen cooled germanium detector. The $488 \mathrm{~nm}$ line of an Ar laser was used as excitation source.

\section{Results and discussion}

Before implantation the quality and composition of the samples were studied by RBS. The spectra obtained for the two films studied are shown in figure $1 \mathrm{a}, \mathrm{b}$ where the continuous line represents the best fit obtained with the RUMP code. Both films have a uniform In distribution over depth and the layer thickness was converted in length units assuming Vegard's law [11] to obtain the density value for the films according the measured composition. The film of figure 1a has an indium composition of 7.5 at $\%$ and a thickness of $175 \pm 10 \mathrm{~nm}$. The minimum yield (the ratio between backscattering yield from random and aligned spectra behind the surface region) is $12 \%$ along the [0001] direction. Since the value of the minimum yield expected for a perfect crystal is of the order of $2 \%$ this high value is an indication for the presence of defects in the film. The second film (figure 1b) has an In concentration of 19 at $\%$ and a thickness of $620 \pm 10 \mathrm{~nm}$. The minimum yield is $23 \%$ revealing a worse quality, which agrees with previous studies suggesting that the increase of In leads to high defect levels. This is a consequence of the strain in the film due to the incorporation of high In concentrations.

After implantation the overlap of the [0001] aligned and the random spectra in the whole implanted region for both $\mathrm{InGaN}$ films indicates the amorphization of this region. The depletion of In from this region becomes also evident. These results clearly show that the presence of In makes the alloy less damage resistant. Indeed, it is known that to amorphize $\mathrm{GaN}$ it is necessary to implant high fluences. For example, in the case of Er a fluence of the order of $5 \times 10^{15} \mathrm{Er}^{+} / \mathrm{cm}^{2}$ is required to reach the amorphous state [12]. The strain present in the films could be the driving force responsible for this easy amorphization. The release of In from the surface is most likely related to preferential sputtering since no beam heating effects were expected due to the low beam current density during the implantation $\left(\leq 0.5 \mu \mathrm{A} / \mathrm{cm}^{2}\right)$. This is in agreement with the annealing behavior where no loss of In was observed up to $500^{\circ} \mathrm{C}$ as we can see in the spectra of figure $1 \mathrm{a}$. In fact we found that even after annealing at $500^{\circ} \mathrm{C}$ the damage profiles do not show significant changes in both samples. Since we were unable to recover the damage for this fluence we implanted a film with $1 \times 10^{13} \mathrm{~cm}^{-2}$ of the radioactive isotope ${ }^{167} \mathrm{Tm}$ in order to prevent amorphization. Emission channeling patterns were recorded immediately following room temperature implantation and after annealing up to $900^{\circ} \mathrm{C}$. Channeling effects were observable already in the as-implanted state (not shown) and improved by $30 \%$ following annealing to $400^{\circ} \mathrm{C}$ [Figs. 2 (a-c)]. In order to derive the ${ }^{167 \mathrm{~m}} \mathrm{Er}$ lattice site, the experimental patterns were compared to the results of 
simulations of Er located in substitutional $\mathrm{In} / \mathrm{Ga}$, substitutional $\mathrm{N}$ and a variety of different interstitial sites, the locations of which we have described in Ref. [Wahl 00]. The best fits of theoretical emission patterns to the experimental yields are shown in Figs. 2 (d-f) and correspond to 33\%, 18\% and 15\% of emitter atoms on substitutional InGa sites $S_{\text {InGa }}$ with root mean square displacements of $0.060 \AA$ and the remaining part occupying random lattice sites. Erbium atoms on other highly symmetric lattice sites than $\mathrm{S}_{\mathrm{InGa}}$ could not be established. Further annealing of the sample above $400^{\circ} \mathrm{C}$ up to $900^{\circ} \mathrm{C}$ slightly improved the fraction of $\mathrm{Er}$ on $\mathrm{S}_{\mathrm{InGa}}$ sites by a few percent. Note that the fractions of Er atoms on $\mathrm{S}_{\mathrm{InGa}}$ sites derived from the [ $\overline{1} 102]$ and $[\overline{2} 113]$ measurements are only about one half of that of the [0001] direction. Most likely this is related to the imperfect crystal quality of the sample, either because the offsurface measurements suffer from the increase in dechanneling by crystal defects due to the longer electron path, or because the InGaN film generally exhibits a better crystalline quality along its [0001] growth direction.

The optical properties observed after implantation are coherent with the increase of damage in the films and a reduction of In content. Absorption measurements before and after implantation are shown in figure 3 . We can see an effective gap of $3.14 \mathrm{eV}$ for the film before the implantation, which almost disappears after the implantation. The second step $(3.34 \mathrm{eV})$ corresponding to the $\mathrm{GaN}$ remains stable. Both films do not show any Er optical activity after the implantation. Annealing at $400^{\circ} \mathrm{C}$ incorporates some ions into optical active sites and the $1.54 \mu \mathrm{m}$ emission associated to the ${ }^{4} \mathrm{I}_{13 / 2} \rightarrow{ }^{4} \mathrm{I}_{15 / 2}$ transition of $\mathrm{Er}^{3+}$ is observed. The emission, shown in figure 4, was only observed in the sample with the lower In concentration and a decrease of $12 \%$ on the intensity of the $1.53 \mu \mathrm{m}$ line is observed at 250K [13]. Since the samples were subjected to the same treatment the difference in the optical activation of Er could be related to different defect configurations surrounding the erbium. The different In content is probably the reason for that and the defects will act as non radiative paths.

\section{Conclusions}

We have shown the possibility to dope InGaN/GaN layers with Er using ion implantation. During the implantation of $1 \times 10^{15} \mathrm{Er}^{+} / \mathrm{cm}^{2}$ the implanted region turns amorphous and preferential sputtering of In is observed. A fraction of the Er ions are incorporated in optically active sites for layers with an In content of 7 at $\%$ after annealing at $400^{\circ} \mathrm{C}$. For films with In concentration of 19 at $\%$ no optical activity was found. Lattice site location with emission channeling shows that Er goes partly into InGa sites after implantation. From the $\mathrm{EC}$ data we conclude that the recovery of the implantation damage was most efficient during the annealing at $400^{\circ} \mathrm{C}$ leading to an incorporation of at least $15-33 \%$ into substitutional InGa sites.

\section{Acknowledgements}

This work was partially supported by the EC under contract No: HPRN-CT-2001-00297. S. Pereira and U. Wahl acknowledge the financial support from Fundação para a Ciência e Tecnologia throught the contracts (BD/859/2000) and (BPD/5536/2001) respectively.

\section{References}

[1] B.Gil Group III Nitride Semiconductor Compounds, Physics and Applications, Oxford Science Publications (Oxford 1998).

[2] S. Nakamura, Science (1998) 281

[3] S. Pereira, R. Correia, T. Monteiro, E. Pereira, E. Alves, A.D. Sequeira, N. Franco, Appl. Phys. Lett. 78 (2001) 2137.

[4] K.P. O Donnell, R. W. Martin, P.G. Middleton, Phys. Rev. Lett. 82 (1999) 237.

[5] A. Polman, J. Appl. Phys. 82 (1997) 1.

[6] C. H.Qiu, M. W. Leksonon, J. I. Pankove, J. T. Torvik, R. J. Feuerstein and F. Namar, Appl. Phys. Lett. 66 (1995) 562.

[7] R.G. Wilson, R. N. Schwartz, C.R. Abernathy, S. J. Pearton, N. Newman, M. Rubin, T. Fu and J. M. Zavada, Appl. Phys. Lett. 65 (1994) 992. 
[8] T. Monteiro, J. Soares, M. R. Correia and E.Alves, J. Appl. Phys. 89 (2001) 6183.

[9] U. Wahl, J.G. Correia, S. Cardoso, J.G. Marques, A. Vantomme, G. Langouche and the ISOLDE collaboration, Nucl. Instr. and Meth. B 136-138 (1998) 744.

[10] U. Wahl, A. Vantomme, J. De Wachter, R. Moons, G. Langouche, J.G. Marques, J.G. Correia and the ISOLDE collaboration, Phys. Rev. Lett. 79 (1997) 2069.

[11] L. Vegard, Z. Phys. 5 (1921) 17.

[12] E.Alves, M.F. da Silva, J.C. Soares, J.Bartels, R.Vianden, C.R.Abernathy, S.J. Pearton, MRS

Internet J. Nitride Semicond.Res. 4S1,G11.2(1999)

[13]M.R. Correia, S. Pereira, A. Cavaco, E. Pereira, E. Alves, Appl. Phys. Lett. 80 (2002) 4504.
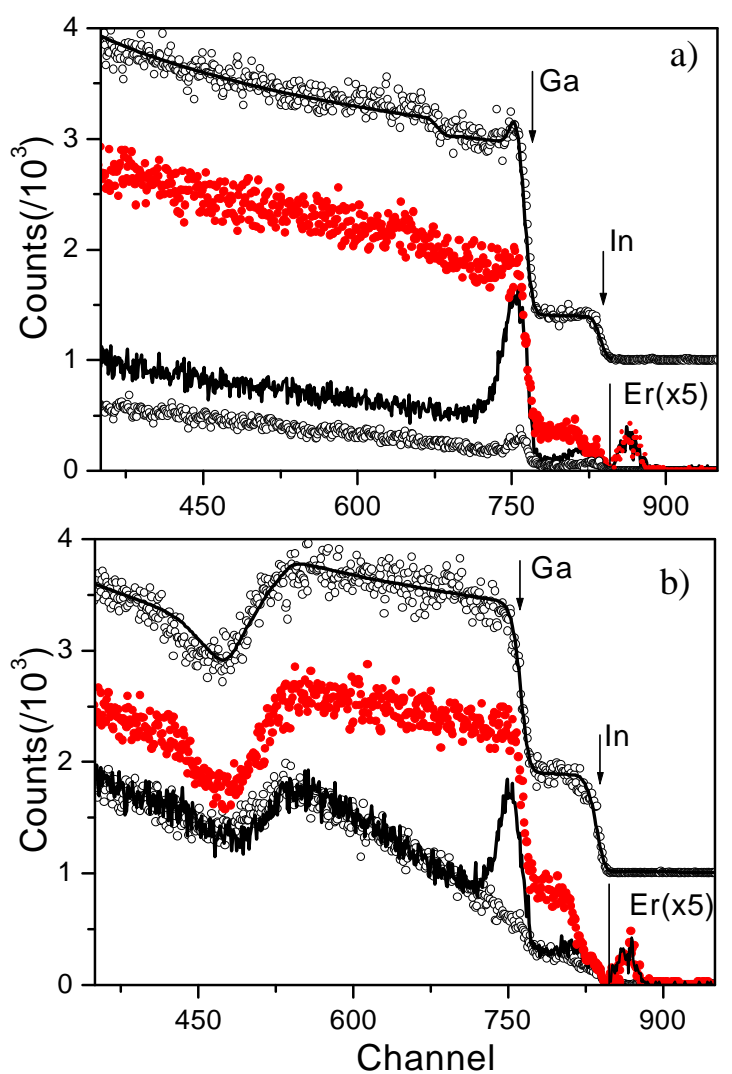

Fig. 1:-a) RBS/C spectra taken along the [0001] axis and in random orientation before (open symbols) and after Er implantation and annealing at $400^{\circ} \mathrm{C}$. A composition of $\operatorname{In}_{.07} \mathrm{Ga}_{.93} \mathrm{~N}$ was derived from the RUMP simulation (continuous line in the random spectrum before implantation). The as implanted spectra (not shown) reveal the same damage and In loss. b) The same for a film with a composition of $\mathrm{In}_{.19} \mathrm{Ga}_{81} \mathrm{~N}$. Note the vertical displacement of the random spectrum obtained before implantation. 


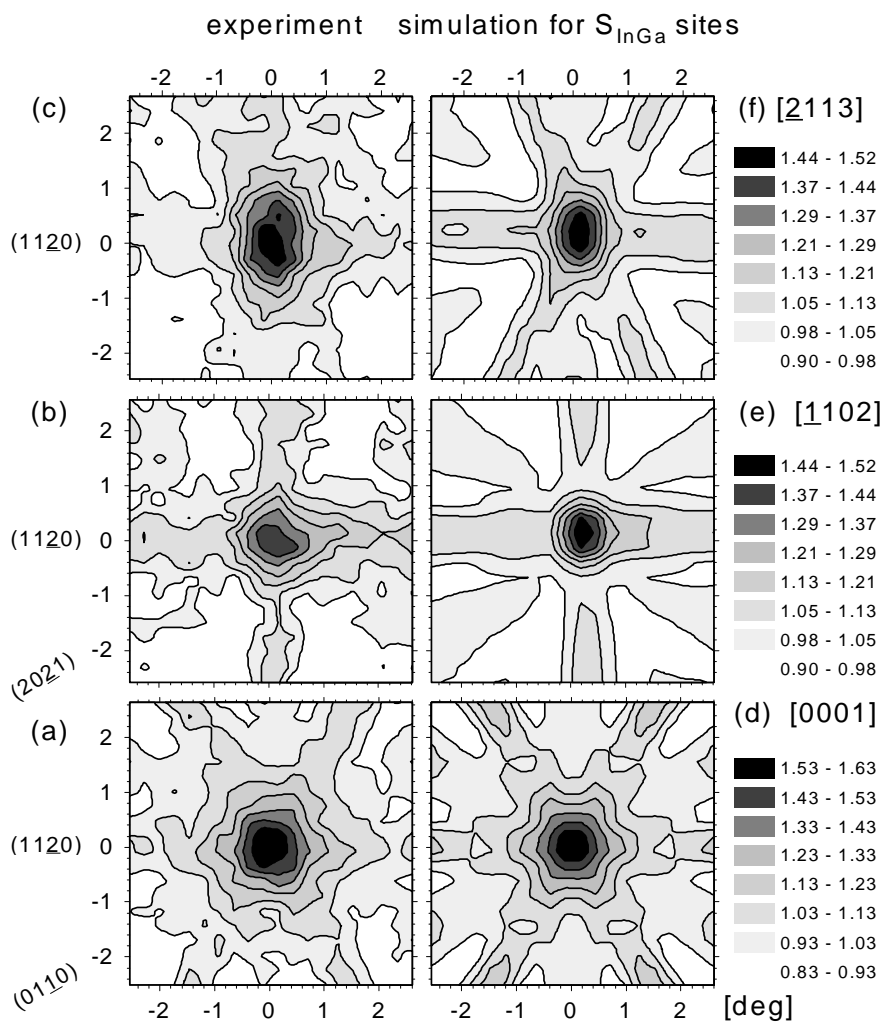

Fig. 2: Conversion electron emission channeling patterns from ${ }^{167 \mathrm{~m}} \mathrm{Er}$ in $\mathrm{In}_{0.19} \mathrm{Ga}_{0.81} \mathrm{~N}$ around the [0001] (a), [ $\overline{1} 102]$ (b) and [ $\overline{2} 113]$ (c) axes. Panels (d)-(f): best fits of simulated channeling patterns for Er on $\mathrm{S}_{\mathrm{InGa}}$ sites to the experimental yields. 


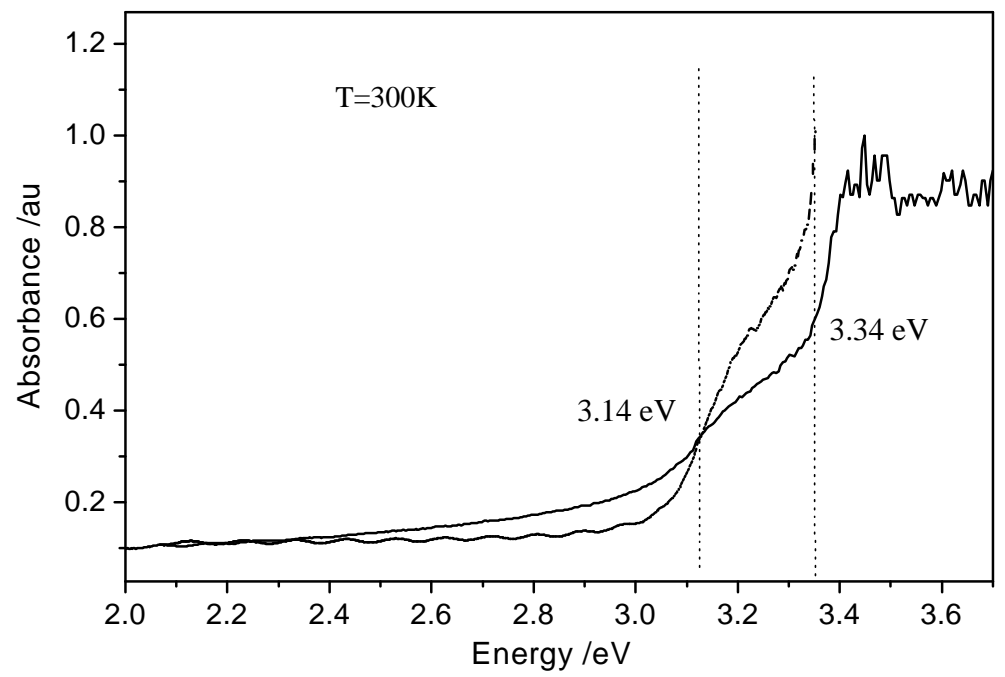

Fig. 3: Absorption spectra before (dashed) and after implantation (continuous) for the film $\operatorname{In}_{.07} \mathrm{Ga}_{93} \mathrm{~N}$.

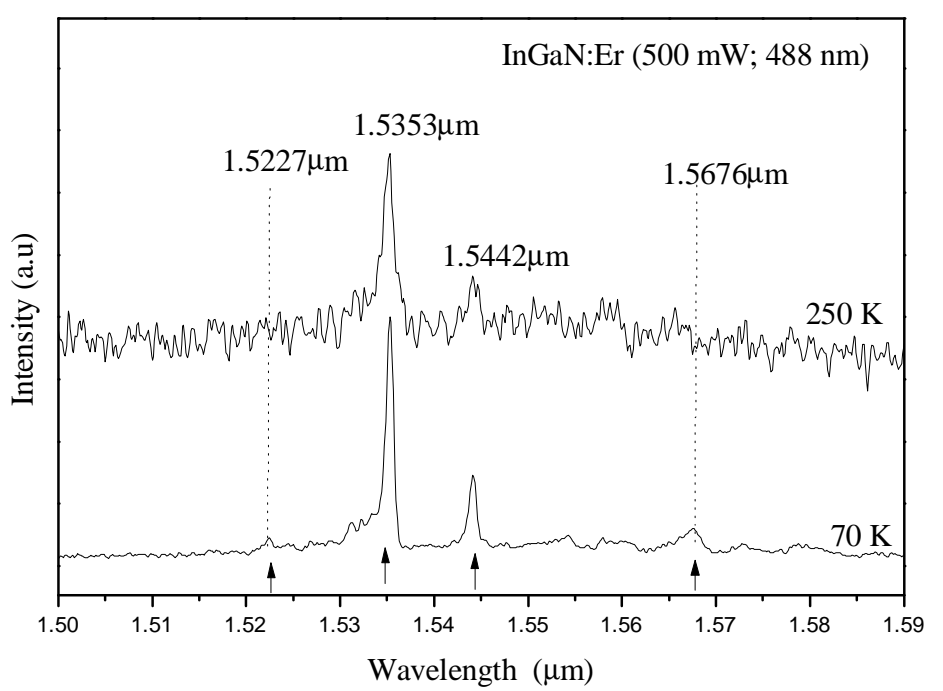

Fig. 4: PL spectrum measured at 70 and $250 \mathrm{~K}$ after annealing at $400^{\circ} \mathrm{C}$ for film $\operatorname{In}_{.07} \mathrm{Ga} .{ }_{93} \mathrm{~N}$. 